\title{
Protection of small-cell lung cancer circulating tumor cells by cellular fragmentation
}

\author{
Barbara Rath ${ }^{1}$, Adelina Plangger ${ }^{1}$, Doris Moser ${ }^{2}$, Maximilian Hochmair ${ }^{3}$, Ernst Ulsperger ${ }^{4}$, Gerhard $^{-}$ \\ Hamilton ${ }^{1}$ \\ 'Department of Vascular Surgery, Medical University of Vienna, Vienna A-1190, Austria. \\ 2Department of Cranio-Maxillofacial and Oral Surgery, Medical University of Vienna, Vienna A-1090, Austria. \\ ${ }^{3}$ Hospital Floridsdorf, Vienna A-1210, Austria. \\ ${ }^{4}$ Hospital Horn, Horn A-3580, Austria.
}

Correspondence to: Dr. Gerhard Hamilton, Department of Vascular Surgery, Medical University of Vienna, Spitalgasse 23, Austria A-1090.E-mail: gerhard.hamilton@meduniwien.ac.at

How to cite this article: Rath B, Plangger A, Moser D, Hochmair M, Ulsperger E, Hamilton G. Protection of small-cell lung cancer circulating tumor cells by cellular fragmentation. J Cancer Metastasis Treat 2020;6:30. http://dx.doi.org/10.20517/2394-4722.2020.51

Received: 25 May 2020 First Decision: 14 Jul 2020 Revised: 17 Jul 2020 Accepted: 22 Jul 2020 Published: 17 Sep 2020

Academic Editor: Wei Zhang Copy Editor: Cai-Hong Wang Production Editor: Jing Yu

\begin{abstract}
Aim: Small-cell lung cancer (SCLC) disseminates aggressively and may exhibit high chemoresistance and poor survival rates. In this study, we aimed to investigate a new mechanism of drug resistance for SCLC circulating tumor cells (CTCs).
\end{abstract}

Methods: SCLC CTC cell lines $(n=4)$ which shed cellular fragments (MAT), as demonstrated by light and scanning electron microscopy, are compared to permanent SCLC lines. Selected proteins are detected by proteome arrays and the functional impact of MAT is studied using cytotoxicity tests involving cisplatin and Topotecan.

Results: The SCLC CTC lines revealed layers of attached cellular fragments with a range of decreasing sizes from intact cells (approximately $12 \mu \mathrm{m}$ ) down to small debris (approximately $2 \mu \mathrm{m}$ ) which are not detectable in permanent SCLC lines. Intact SCLC CTC clusters represent cores of these fragment-coated spheroids. Proteome profiling of MAT revealed a protein pattern similar to intact cells. Chemosensitivity tests employing SCLC and SCLC CTC lines with chemotherapeutics used in therapy of SCLC demonstrated an inhibitory activity of MAT on the resulting cytotoxicity.

Conclusion: Generation of cell-associated debris by SCLC CTCs offers protective effects against cytotoxic drugs, representing a novel mechanism allowing survival of SCLC CTCs in patients.

cC) (i) (c) The Author(s) 2020. Open Access This article is licensed under a Creative Commons Attribution 4.0 International License (https://creativecommons.org/licenses/by/4.0/), which permits unrestricted use, sharing, adaptation, distribution and reproduction in any medium or format, for any purpose, even commercially, as long as you give appropriate credit to the original author(s) and the source, provide a link to the Creative Commons license, and indicate if changes were made.

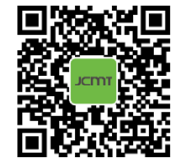


Keywords: Small cell lung cancer, circulating tumor cells, shedding, topotecan

\section{INTRODUCTION}

Small cell lung cancer (SCLC) constitutes approximately 15\% of all lung cancers and is characterized by rapid metastasis, universal drug resistance upon recurrence which subsequently leads to a poor prognosis in patients ${ }^{[1]}$. The initial choice of chemotherapy for patients with extended disease (ED)-SCLC includes using platinum-based regimens in combination with etoposide and immune checkpoint inhibitors. This yields high response rates but tumors may invariably relapse and exhibit increased chemoresistanceresulting in a 2 -year survival less than $10 \%{ }^{[2]}$. A host of chemically unique therapeutics failed in clinical trials of SCLC and the mechanisms of drug resistance have yet to be conclusively resolved thus far ${ }^{[3]}$. The recent use of novel drug combinations yields a minor prolongation of the overall survival but at a cost of increasing side effects in light of frequent COPD exacerbations and sequelae of smoking. In contrast to NSCLC, SCLC does not have clear dependence on driver mutations and shows inactivation of the tumor suppressor genes p53 and $\mathrm{RB} 1^{[4]}$. Recurrent tumors grow rapidly and may show universal necrotic regions due to the lack of supply of blood vessels. Dissemination of SCLC appears to be correlated with a high count of circulating tumor cells (CTCs), exceeding the CTC numbers found in carcinomas of breast, colon and prostate by several magnitudes ${ }^{[5]}$. Nevertheless, only a small fraction of the highly heterogenous CTCs is competent to generate metastases. Several studies have reported a higher metastatic potential of CTC aggregates, defined as clusters of different cells ${ }^{[6]}$.

The extreme CTC count that is present in SCLC patients allowed us to expand eight permanent CTC lines from blood samples in vitro. Our data show these CTCs include typical SCLC markers such as CD56/ NCAM, enolase-2 and chromogranin, which are EpCAM-positive ${ }^{[7]}$. Furthermore, all of these CTC lines demonstrated spontaneous formation of larger spheroids under regular cell culture conditions, exhibiting high chemoresistance when compared with the corresponding single cell suspensions ${ }^{[8]}$. The global drug resistance to structurally unrelated chemotherapeutics may be appropriately explained by a physical factor represented by the barrier of spheroids, limiting drug access to tumor cells in sufficient concentrations. A unique feature of SCLC CTCs is the release or shedding of cellular particles, which appear as free-floating debris or as coat containing cores of intact cell aggregates. Release of such cell fragments is not detectable in established cell lines from SCLC tumor tissues. The present work investigates the properties of these cell fragments and their possible role in protection of cells against chemotherapeutics.

\section{METHODS}

\section{Cell lines and reagents}

SCLC26A cell line was established in our laboratory from a pleural effusion fluid sample of an SCLC patient prior to treatment. NCI-H417, DMS153 and NCI-H69 cell lines were established from primary SCLCs before treatment and GLC16 from a recurrent tumor. These cell lines were obtained from the Finsen Center, Copenhagen, Denmark. The SCLC CTC cell lines BHGC7, 10, 16, 26 and 91 were established from blood samples of ED-SCLC patients at our institution ${ }^{[7,9]}$. In brief, leucocytes and CTCs were isolated by gradient centrifugation (Ficoll-Hypaque; Sigma-Aldrich, St. Louis, MO, USA) and the cell preparation was cultivated in serum-free RPMI-1640 medium supplemented with insulin, IGF-1, transferrin, and selenite until appearance of clonal outgrowth. Following expansion of the CTC clones, cells were transferred to regular medium containing fetal bovine serum (FBS). Tissue culture medium consisted of RPMI-1640 medium (Sigma-Aldrich) supplemented with 10\% FBS (Seromed, Berlin, Germany) andPenicillinStreptomycinSigma-Aldrich). Single cell suspension of the CTC lines spontaneously form tumorospheres (TOS) in regular tissue culture. Blood collection and generation of cell lines was performed according to the Ethics Approval protocol \#366/2003 by the Ethics Committee of the Medical University of Vienna, Vienna, Austria. All other chemicals were obtained from Sigma-Aldrich. 


\section{Cytotoxicity assays}

$1 \times 10^{4}$ cells in the form of single cells or TOS in $100 \mu \mathrm{L}$ medium were distributed to individual wells of 96well microtiter plates (TPP, Trasadingen Switzerland) and ten 2 -fold dilutions of the test compounds were added from stock dilutions as described previously. Assays were performed in triplicates. The plates were incubated for four days under tissue culture conditions and viable cells then detected using a modified MTT assay (EZ4U, Biomedica, Vienna, Austria). The respective dilutions of the compounds tested were present for the entire incubation period. $\mathrm{IC}_{50}$ values were determined from dose-response curves using Origin 9.1 software (OriginLab, Northampton, MA, USA).

\section{Scanning electron microscopy}

For scanning electron microscopy (SEM), samples were washed twice with phosphate-buffered saline, fixed in Karnovsky's fixative (Morphisto ${ }^{\star}$, Frankfurt am Main, Germany) and dehydrated in a graded ethanol series. Ethanol dehydration was followed by hexamethyldisilazane drying (HMDS, Sigma-Aldrich) followed by gold sputtering (Sputter Coater, SC502, Polaron, Fisons Instruments ${ }^{\bullet}$, England) and examination performed using a scanning electron microscope (JSM 6310, Jeol Ltd. ${ }^{\bullet}$, Japan).

\section{Western blot array}

Biomarkers were analyzed using the ARY026 Proteome Profiler Array (R\&D Systems, Minneapolis, MN, USA), which detects 84 cancer-related proteins according to manufacturer's instructions. Experiments were performed in duplicate and the different tests were calibrated using the six reference spots included for each individual membrane. Arrays were evaluated using ImageJ (NIH, Bethesda, MD, USA) and Origin 9.1 software (OriginLab, Northampton, MA, USA).

\section{Statistical analysis}

Statistical significance was tested by $t$-tests and $P<0.05$ regarded as statistically significant difference using Origin software (Originlab, Northampton, MA, USA).

\section{RESULTS}

\section{Physical structure of SCLC CTC spheroids}

In our laboratory, SCLC CTC cell lines were obtained from blood samples of patients diagnosed with EDSCLC prior to initiation of second-line chemotherapy. These cell lines show release of cellular fragments by intact cells or covering of the SCLC CTC spheroids by layers of such fragments. The cellular fragments were termed material (MAT). A CTC BHGc91 cluster encased in subcellular material is depicted in Figure 1A in light microscopy. Physical removal of the cover by vigorous pipetting releases a core assembly of intact tumor cells [Figure 1B].

\section{Effects of MAT on the chemosensitivity of SCLC cell lines}

MAT released into the cell supernatants were collected after centrifugation and added to chemosensitivity assays which employ cisplatin and Topotecan, respectively. Two typical experiments and their data, using BHGc10 CTCs are shown in Figure 2A and B. The dose-response curves reveal that addition of MAT91 decreases the chemosensitivity of CTC cells to cisplatin and topotecan to a large extent. In the presence of MAT, a fraction of the SCLC CTC cells continue to survive at the highest concentrations of both chemotherapeutics tested.

In a subsequent chemosensitivity test, the viable cell content of a MAT91 fraction was eliminated by several freeze-thaw cycles. The absence of any contaminating living cells in this preparation resulted in a resistance-enhancing effect on the topotecan sensitivity of BHGc10 CTCs [Figure 3]. In this experiment, the protective effect was not exhibited for topotecan concentrations ranging from $2.5-10 \mu \mathrm{g} / \mathrm{mL}$. 

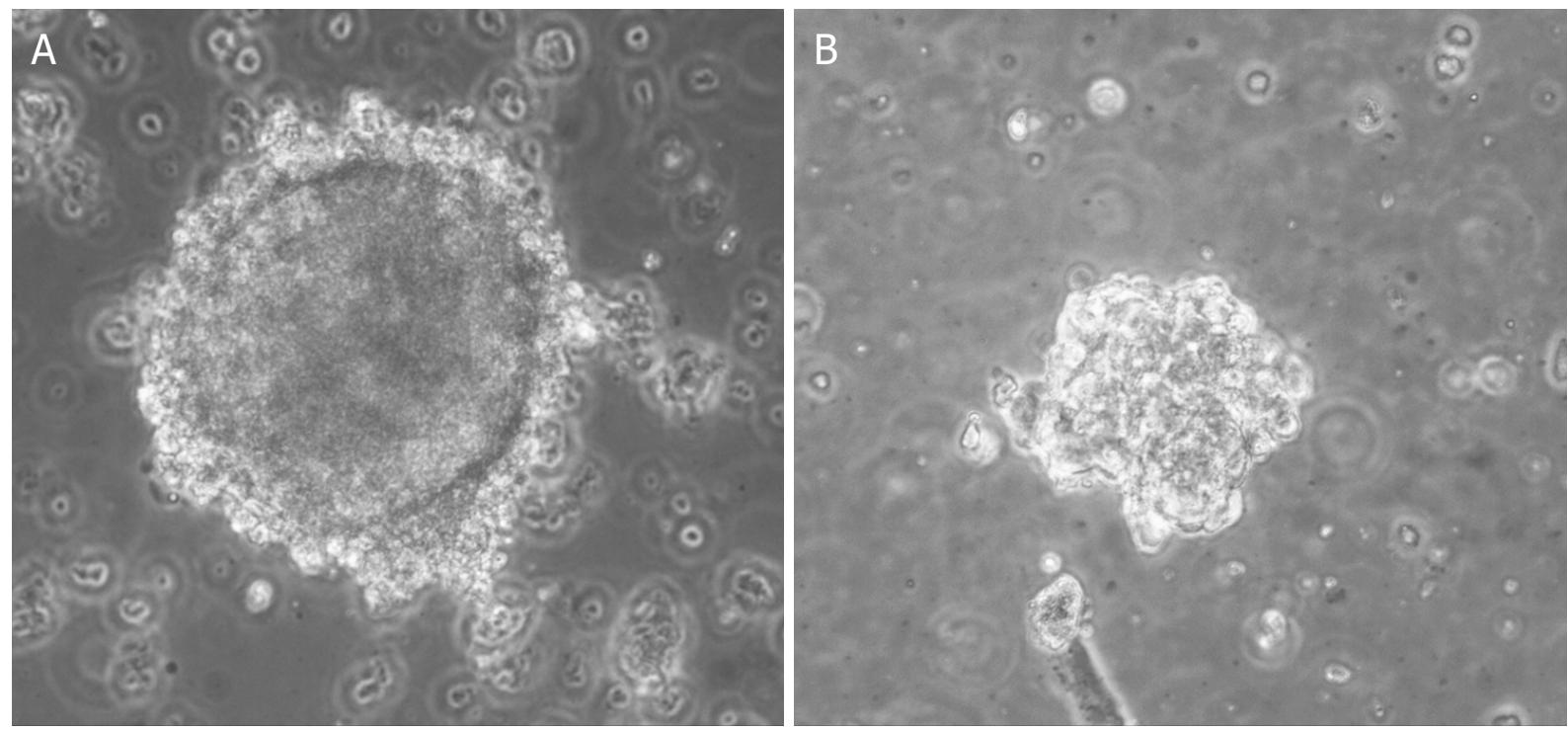

Figure 1. Light microscopy of a MAT-covered tumorosphere (A) and the same cell preparation after vigorous pipetting (B). MAT: material

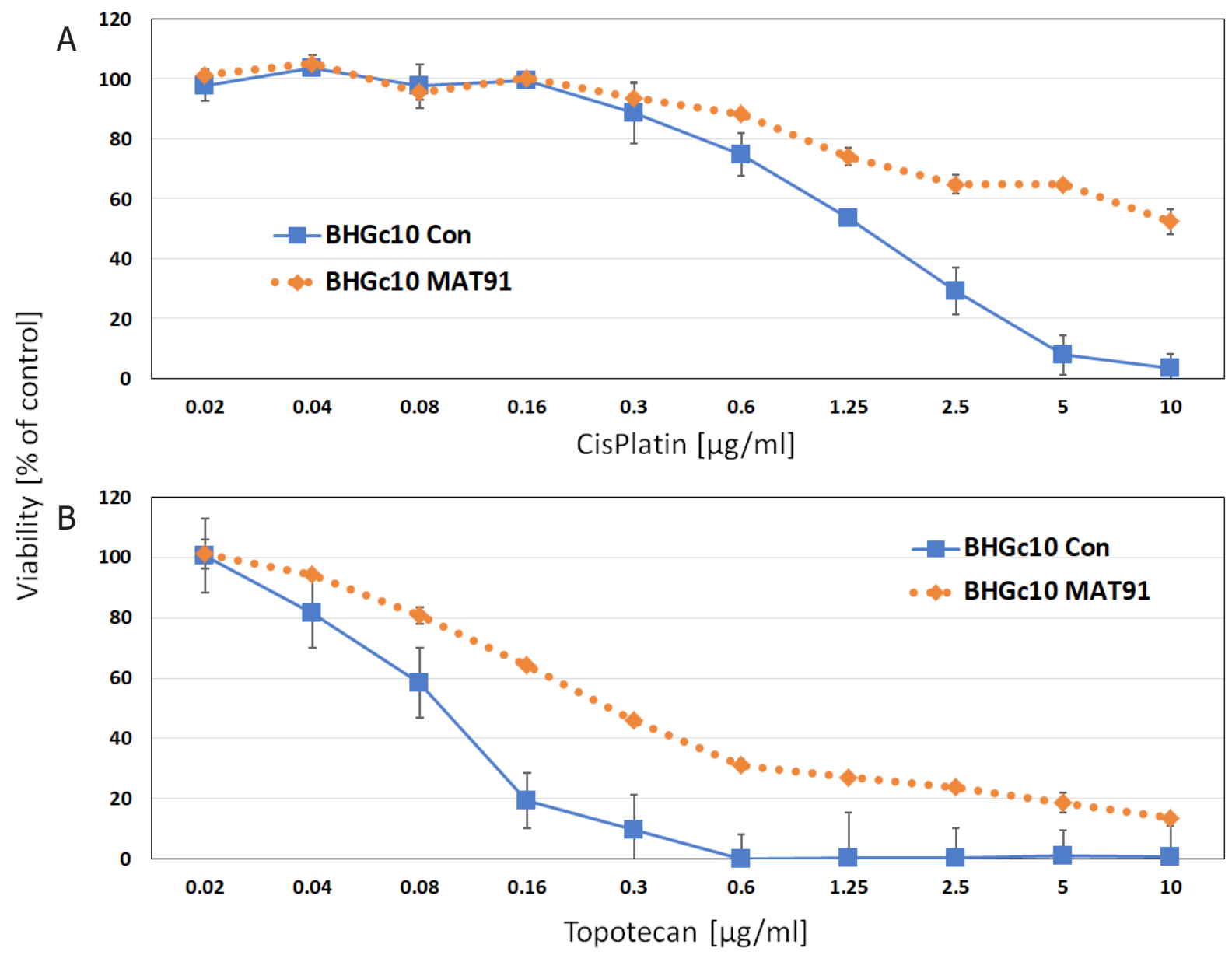

Figure 2. Cytotoxicity testing of BHGc10 SCLC CTCs employing cisplatin (A) or topotecan (B) showing controls and MAT supplementation, respectively (Error bars represent mean values \pm SD). CTCs: circulating tumor cells; SCLC: small-cell lung cancer; MAT: material 


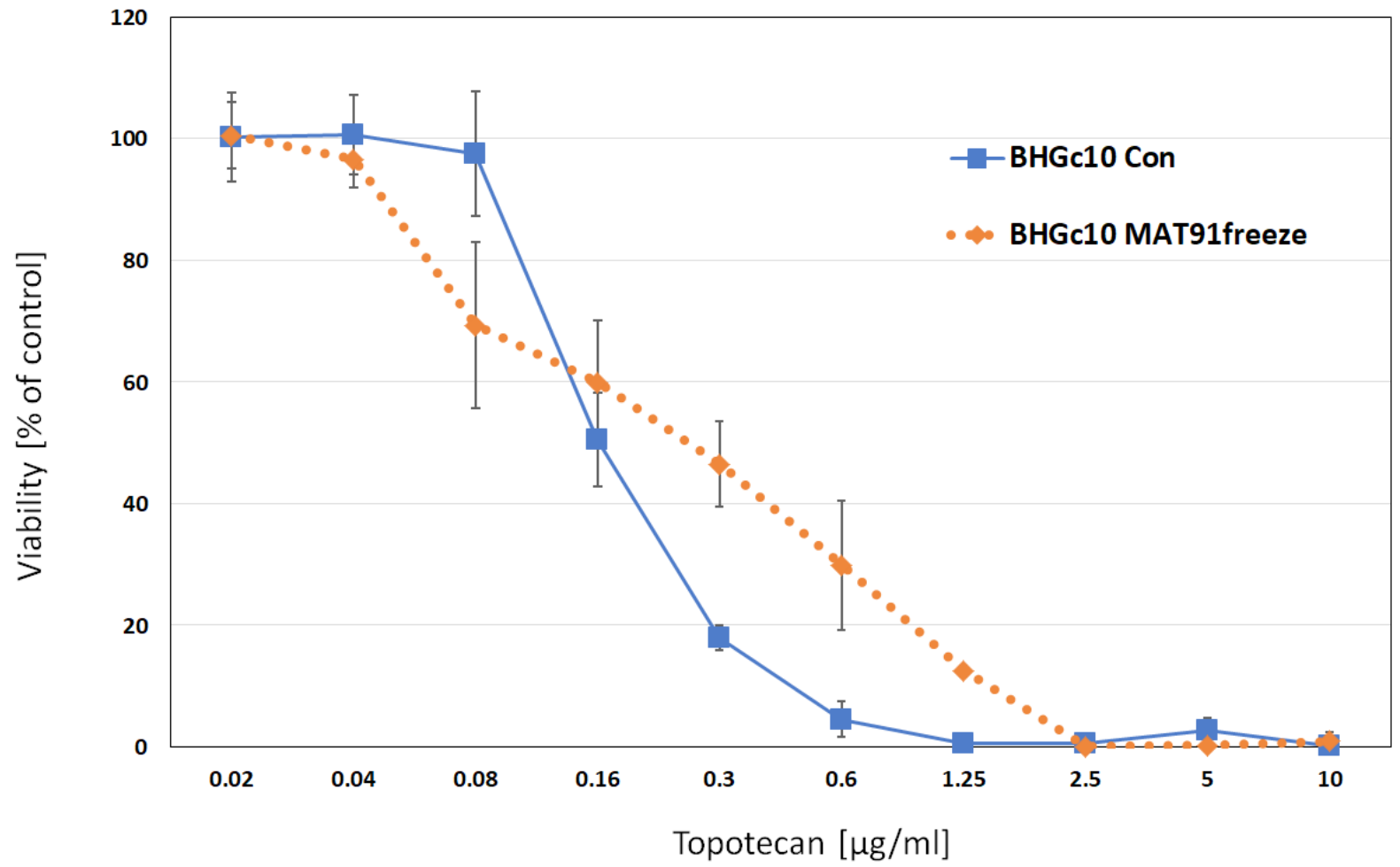

Figure 3. Cytotoxicity test of BHGC10 SCLC CTCS employing topotecan showing the control and MAT supplementation, respectively (Error bars represent mean values $\pm \mathrm{SD}$ ). For this experiment MAT was pretreated with a freeze-thaw cycle. CTCs: circulating tumor cells; SCLC: small-cell lung cancer; MAT: material

Results of the chemosensitivity tests are summarized in Figure 4. Of the nine cell lines shown, only SCLC26A is derived from a pleural effusion and this demonstrated a decreased chemosensitivity to topotecan in the presence of MAT. All other cell lines exhibited increased resistance upon inclusion of MAT, including pleural cell line S457 and established cell lines NCI-69, NCI-H417 and DMS153.

\section{Size distribution of MAT}

MAT was analyzed for size distribution of its fragments and their appearances using SEM [Figure 5]. The results for BHGc7 CTCs show a continuous decrease in the size of their cellular fragments ranging from fully intact cells (10-12 $\mu \mathrm{m})$ down to small sizes of approximately $2 \mu \mathrm{m}$. SEM also demonstrated that the cellular fragments exhibit a range of sizes and an appearance of degraded cells with remaining cytoskeletal structures.

For BHGc7, a wide range of cancer-related proteins were compared between the native cell line and MAT release. We used the ARY026 Proteome Profiler Array because in this particular cell line, its cell fragments demonstrate intact membranes in the beginning [Figure 6]. Although there was some variability in the expression of proteins, markers including p53, Enolase-2 and EpCAM were preserved upon release of the fragments. In general, MAT represents the normal cellular protein content of the cell of origin as far as testing with this specific array.

\section{DISCUSSION}

The prognosis of SCLC has not improved significantly in recent times despite the introduction of novel therapeutics and immunotherapy ${ }^{[2,3]}$. The addition of anti-PD-L1 atezolizumab to chemotherapy for EDSCLC has increased the median overall survival by 2 months and the median progression-free survival 


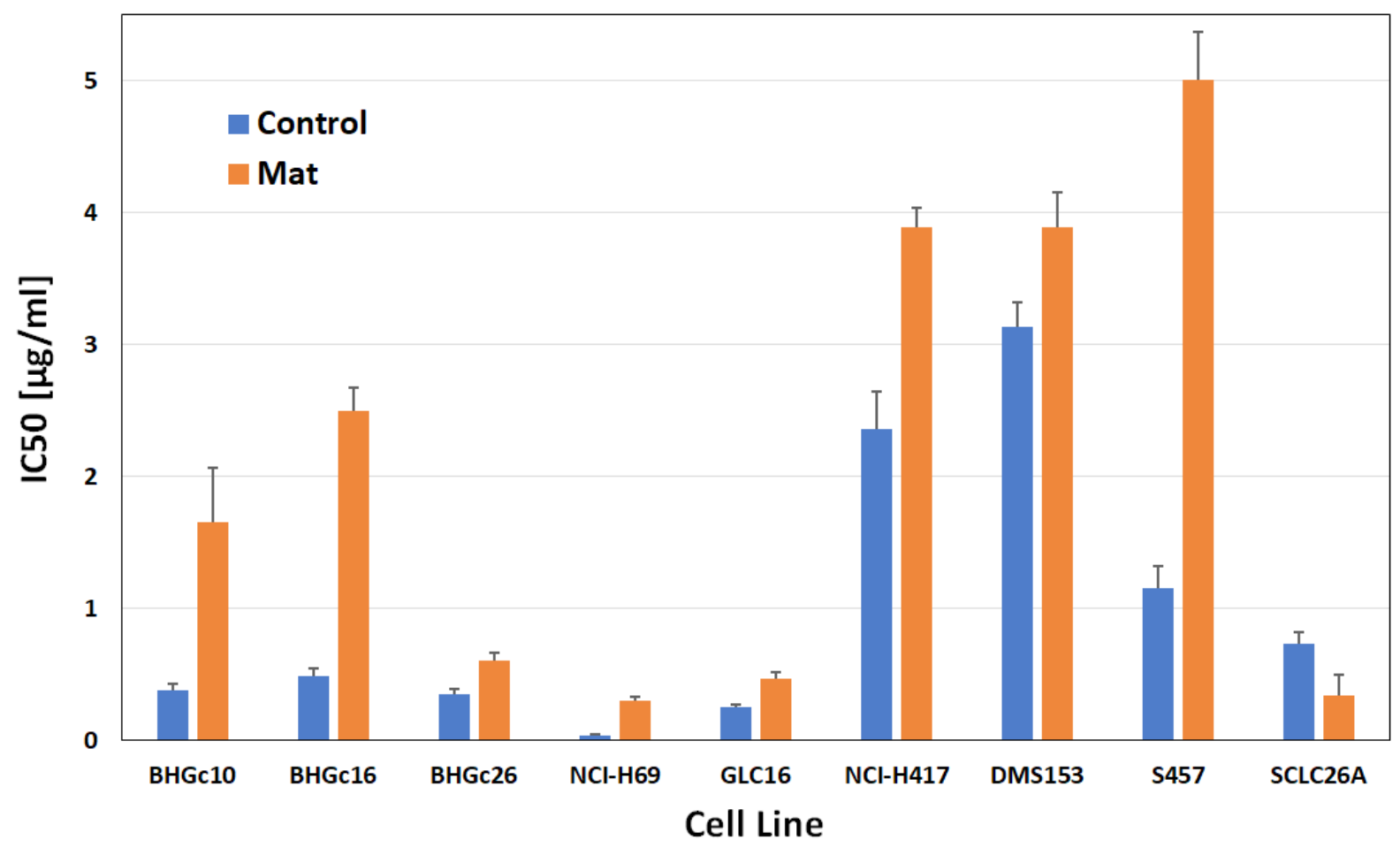

Figure 4. Summary of the $I C_{50}$ values for Topotecan and cell lines either as medium controls or supplemented with MAT (Error bars are represented by mean values \pm SD; all differences are statistically significant)

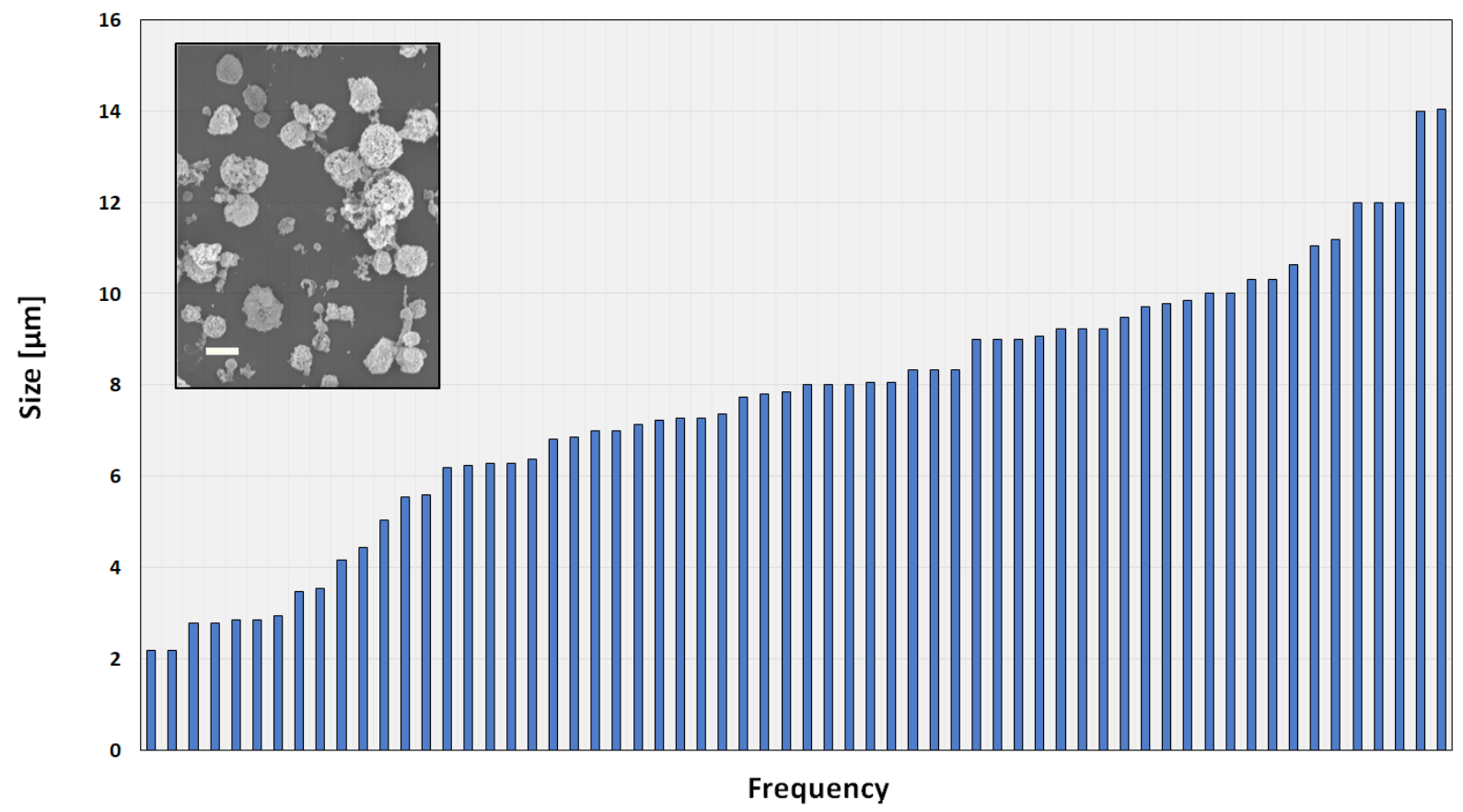

Figure 5. Size distribution of MAT derived from BHGC91 SCLC CTCs. The insert depicts a SEM preparation of BHGc91 MAT (magnification 2000x, the bar represents $10 \mu \mathrm{m})$. CTCs: circulating tumor cells; SCLC: small-cell lung cancer; MAT: material

from 4.3 to 5.2 months. This constitutes a significant but minor improvement ${ }^{[10]}$. In most cases, SCLC has excellent response to platinum-based first-line treatment but it invariably recurs as drug-resistant tumor 


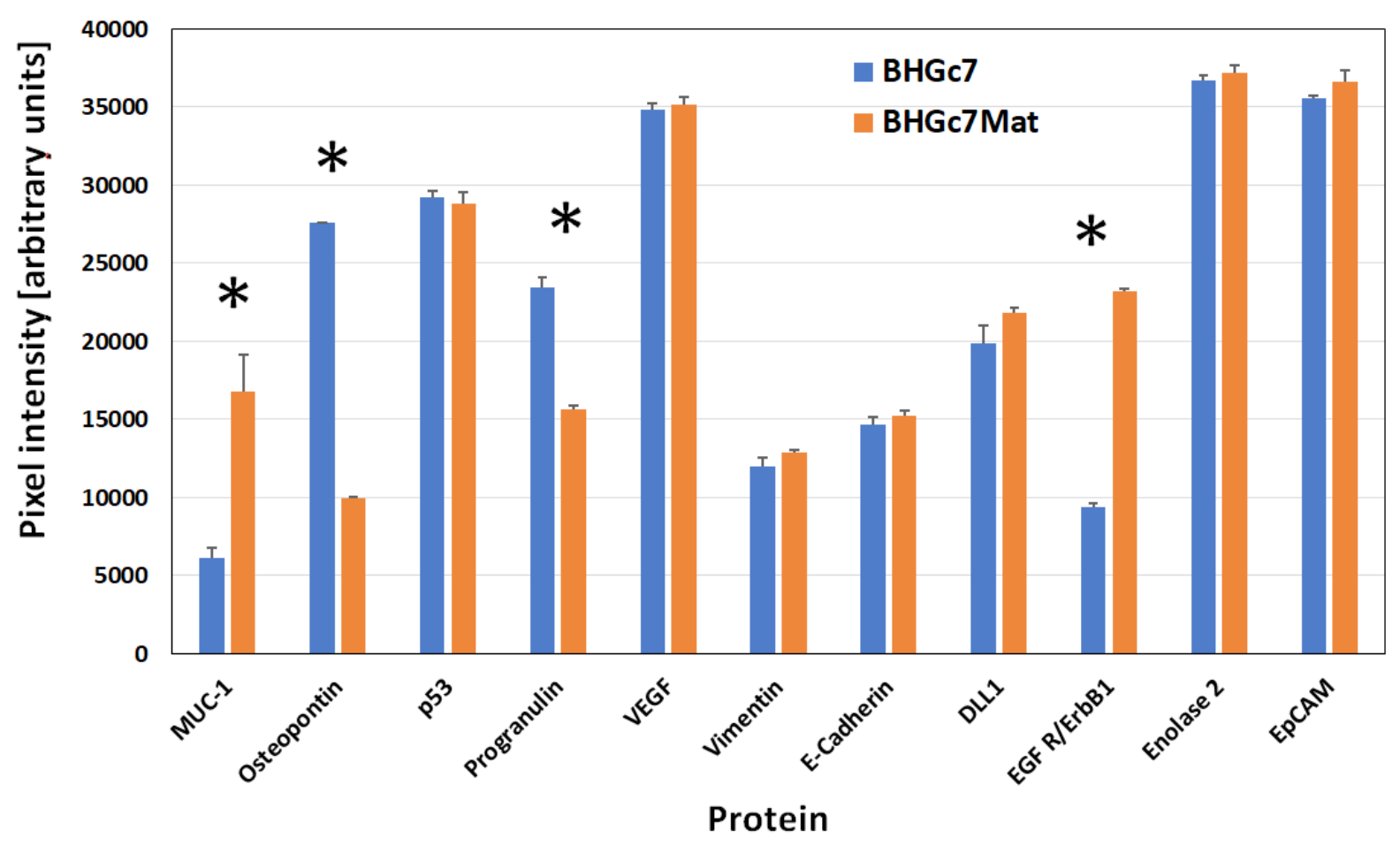

Figure 6. Comparison of selected proteins of the BHGC7 SCLC CTC cell line and its corresponding BHGC7 MAT. The ARY026 array used detects 84 cancer-related proteins *significantly different protein amounts are marked with an asterisk. Error bars represent mean values \pm SD. CTC: circulating tumor cell; SCLC: small-cell lung cancer; MAT: material

within approximately 1-2 years, often with a dismal prognosis. Second-line therapy consisting of topotecan or vincristine-epirubicin-cyclophosphamide regimens results in low response rates of short duration. Addition of further agents or administration of novel agents yields no major improvement with the exception of some progress with immunotherapy in responsive patients ${ }^{[11]}$.

The genome and gene expression of SCLC tumor tissue has been extensively characterized. Apart from inactivation of $\mathrm{p} 53$ and RB1, driver kinases have been detected in minor subpopulations of patients ${ }^{[3]}$. The major tumor-promoting mechanism appears to be a general transcriptional de-regulation, which is difficult to target. Chemoresistance to a host of structurally unrelated compounds in SCLC is not feasibly explained by a matching range of individual counteracting mechanisms and global impairment of cell death has not been overcome, for example, by Bcl2 inhibitors ${ }^{[12]}$. Therefore, the most likely mechanism of drug resistance remains to be presence of physical resistance at the tumor tissue level. The rapidly advancing SCLC recurrences may outgrow their vessel supply resulting in tumor cells near the necrotic area becoming increasingly resistant and aggressive. We have shown previously that SCLC CTCs form large aggregates, termed tumorospheres, spontaneously in tissue culture and that such spheroids exhibit significantly higher levels of resistance to chemotherapeutics as compared to single cell suspensions ${ }^{[7]}$. Such tumorospheres may not exist in the circulation, but they form in capillaries prior to extravasation and generation of metastases ${ }^{[13]}$. Furthermore, our collection of SCLC CTCs exhibit shedding of large quantities of cellular fragments in the presence of intact tumor cells, which can then be cultivated for unlimited passages. For certain SCLC CTC, such as BHGc7, BHGc10, BHGc16 and UHGc5lines, its fragments are released into the surrounding media but for other CTC lines as shown in Figure 1, tumor cell aggregates may be covered by fragments like a complete envelope. This superficially attached cover may be removed with the use of vigorous pipetting, demonstrating a loose association with cells.

Our present results indicate that the MAT has profound effects on chemosensitivity of SCLC CTC and SCLC cell lines through the increase of resistance to topotecan to a large degree ${ }^{[14]}$. This effect is 
largely independent of MAT containing viable material, since this effect is preserved during freeze-thaw cycles, except for very high topotecan concentrations which are not found in patients. Changes in the chemosensitivity of SCLC cells to cisplatin in the presence of MAT was tested but yielded less discernable effects (data not shown). In all likelihood, MAT is still able to bind topotecan via DNA and topoisomerases left, whereas the binding of cisplatin to DNA is impaired by the high sodium concentrations of the medium by preventing the exit of chlorides ${ }^{[15,16]}$. SEM pictures of MAT depict cell fragments without membranes and a sponge-like cytoskeleton. Further analysis of the MAT demonstrates a gradual decrease of the size of the fragments down to approximately $2 \mu \mathrm{m}$. Nevertheless, this dimension remains too large for classical extracellular vesicles which are typically less than $1 \mu \mathrm{m}^{[17]}$.

The role of cellular debris in tumors, either by spontaneous formation or induction by chemotherapy is under investigation. Evidence from animal models indicates that chemotherapy may stimulate tumor initiation, growth, and metastasis partially by tumor-derived cellular debris (e.g., apoptotic/necrotic cells, and cell fragments $)^{[18-21]}$. Similarly, radiation-induced apoptotic tumor cells may promote tumor growth via the Révészphenomenon ${ }^{[22-24]}$. In colon cancer, chemotherapy triggers tumor cell death and the resulting dead cells, or debris, may stimulate angiogenesis, inflammation, and growth ${ }^{[24]}$. Debris induces the release of osteopontin (OPN), which is a marker of poor prognosis. OPN plays important roles in angiogenesis, cell proliferation and metastasis ${ }^{[25-28]}$. Apoptotic tumor cells further stimulate chemotaxis of macrophage and the production of pro-inflammatory cytokines ${ }^{[29]}$. In invasive breast cancers, patients with a high apoptotic index resulted in a shorter overall survival ${ }^{[30]}$. Persistent apoptotic cells may progress to become necrotic cells that release macromolecules including that of degradative enzymes and inhibitory or protumor factors into the local microenvironment ${ }^{[31]}$. The cancer-related protein array showed expression of OPN by BHGc7 and derived MAT, which may possibly play a role in modulating the tumor microenvironment.

Taken together, the SCLC CTCs shed cellular fragments spontaneously without exposure to cytotoxic drugs or environmental stress. In addition to the fragments described for the CTC BHGc91 cell line, other CTC lines which have been established in our laboratory show a comparable and reproducible release of such structures suggesting a general role in SCLC CTCs. The possible release of mediators by this MAT was not tested in these experiements, but the role of these fragments to decrease the chemosensitivity of SCLC cell lines has been established in other cytotoxicity assays. This novel characteristic of SCLC CTC cells may participate in clinical refractoriness to chemotherapy. Furthermore, SCLC can be monitored by the detection of routine neuroendocrine serum markers. In an extension of these assays, blood may be used in the search for particle-associated SCLC markers, which could be more indicative of tumor cell dissemination.

\section{DECLARATIONS}

\section{Acknowledgments}

We wish to thank Dr. T. Hohenheim for continuous endorsement.

\section{Authors' contributions}

Performed experimental work: Rath B, Plangger A

Made the SEM preparations: Moser D

Planned and discussed the investigation: Hochmair M, Ulsperger E

Supervised the study and the writing of the manuscript: Hamilton G

\section{Availability of data and materials}

Not applicable. 


\section{Financial support and sponsorship}

None.

\section{Conflicts of interest}

All authors declared that there are no conflicts of interest.

\section{Ethical approval and consent to participate}

Not applicable.

\section{Consent for publication}

Not applicable.

\section{Copyright}

(C) The Author(s) 2020

\section{REFERENCES}

1. Sabari JK, Lok BH, Laird JH, Poirier JT, Rudin CM. Unravelling the biology of SCLC: implications for therapy. Nat Rev Clin Oncol 2017;14:549-61.

2. Yang S, Zhang Z, Wang Q. Emerging therapies for small cell lung cancer. J Hematol Oncol 2019;12:47.

3. Wang Y, Zou S, Zhao Z, Liu P, Ke C, et al. New insights into small-cell lung cancer development and therapy. Cell Biol Int 2020;44:1564-76

4. George J, Lim JS, Jang SJ, Cun Y, Ozretić L, et al. Comprehensive genomic profiles of small cell lung cancer. Nature 2015;524:47-53.

5. Hodgkinson CL, Morrow CJ, Li Y, Metcalf RL, Rothwell DG, et al. Tumorigenicity and genetic profiling of circulating tumor cells in small-cell lung cancer. Nat Med 2014;20:897-903.

6. Gkountela S, Castro-Giner F, Szczerba BM, Vetter M, Landin J, et al. Circulating tumor cell clustering shapes DNA methylation to enable metastasis seeding. Cell 2019;176:98-112.e14.

7. Klameth L, Rath B, Hochmaier M, Moser D, Redl M, et al. Small cell lung cancer: model of circulating tumor cell tumorospheres in chemoresistance. Sci Rep 2017;7:5337.

8. Hamilton G, Rath B. Role of circulating tumor cell spheroids in drug resistance. Cancer Drug Resist 2019;2:762-72.

9. Hamilton G, Burghuber O, Zeillinger R. Circulating tumor cells in small cell lung cancer: ex vivo expansion. Lung 2015;193:451-2.

10. Horn L, Mansfield AS, Szczęsna A, Havel L, Krzakowski M, et al; IMpower133 Study Group. First-line atezolizumab plus chemotherapy in extensive-stage small-cell lung cancer. N Engl J Med 2018;379:2220-9.

11. Pavan A, Attili I, Pasello G, Guarneri V, Conte PF, et al. Immunotherapy in small-cell lung cancer: from molecular promises to clinical challenges. J Immunother Cancer 2019;7:205.

12. Gadgeel SM. Targeted therapy and immune therapy for small cell lung cancer. Curr Treat Options Oncol 2018;19:53.

13. Hamilton G, Rath B. Insights into mechanisms of tumor dissemination from circulating tumor cell lines of small cell lung cancer. J Cancer Metastasis Treat 2016;2:446-52.

14. Baize N, Monnet I, Greillier L, Quere G, Kerjouan M, et al. Second-line treatments of small-cell lung cancers. Expert Rev Anticancer Ther 2017;17:1033-43.

15. Kitai Y, Kawasaki T, Sueyoshi T, Kobiyama K, Ishii KJ, et al. DNA-containing exosomes derived from cancer cells treated with topotecan activate a STING-dependent pathway and reinforce antitumor immunity. J Immunol 2017;198:1649-59.

16. Siddik ZH. Cisplatin: mode of cytotoxic action and molecular basis of resistance. Oncogene 2003;22:7265-79.

17. Namee NM, O’Driscoll L. Extracellular vesicles and anti-cancer drug resistance. Biochim Biophys Acta Rev Cancer 2018;1870:123-36.

18. Longley DB, Harkin DP, Johnston PG. 5-Fluorouracil: mechanisms of action and clinical strategies. Nat Rev Cancer 2003;3:330-8.

19. De Ruiter J, Cramer SJ, Smink T, van Putten LM. The facilitation of tumour growth in the lung by cyclophosphamide in artificial and spontaneous metastases models. Eur J Cancer 1979;15:1139-49.

20. Ormerod EJ, Everett CA, Hart IR. Enhanced experimental metastatic capacity of a human tumor line following treatment with 5-azacytidine. Cancer Res 1986;46:884-90.

21. Karagiannis GS, Pastoriza JM, Wang Y, Harney AS, Entenberg D, et al. Neoadjuvant chemotherapy induces breast cancer metastasis through a TMEM-mediated mechanism. Sci Transl Med 2017;9:eaan0026.

22. Revesz L. Effect of tumour cells killed by X-rays upon the growth of admixed viable cells. Nature 1956;178:1391-2.

23. Huang Q, Li F, Liu X, Li W, Shi W, et al. Caspase 3-mediated stimulation of tumor cell repopulation during cancer radiotherapy. Nat Med 2011;17:860-6.

24. Correa M, Machado J Jr, Carneiro CR, Pesquero JB, Bader M, et al. Transient inflammatory response induced by apoptotic cells is an important mediator of melanoma cell engraftment and growth. Int J Cancer 2005;114:356-63.

25. Chang J, Bhasin SS, Bielenberg DR, Sukhatme VP, Bhasin M, et al. Chemotherapy-generated cell debris stimulates colon carcinoma 
tumor growth via osteopontin. FASEB J 2019;33:114-25.

26. Ramchandani D, Weber GF. Interactions between osteopontin and vascular endothelial growth factor: implications for cancer. Biochim Biophys Acta 2015;1855:202-22.

27. BandopadhyayM, Bulbule A, Butti R, Chakraborty G, Ghorpade P, et al. Osteopontin as a therapeutic target for cancer. Expert OpinTher Targets 2014;18:883-95.

28. Kale S, Raja R, Thorat D, Soundararajan G, Patil TV, et al. Osteopontin signaling upregulates cyclooxygenase-2 expression in tumorassociated macrophages leading to enhanced angiogenesis and melanoma growth via $\alpha 9 \beta 1$ integrin. Oncogene 2014;33:2295-306.

29. Weigert A, Mora J, Sekar D, Syed S, Brüne B. Killing is not enough: how apoptosis hijacks tumor-associated macrophages to promote cancer progression. AdvExp Med Biol 2016;930:205-39.

30. De Jong JS, van Diest PJ, Baak JP. Number of apoptotic cells as a prognostic marker in invasive breast cancer. Br J Cancer 2000;82:368-73.

31. Gregory CD, Pound JD. Cell death in the neighbourhood: direct microenvironmental effects of apoptosis in normal and neoplastic tissues. J Pathol 2011;223:177-94. 